\title{
FERRAMENTAS DA QUALIDADE NO DESENVOLVIMENTO DE NOVOS PRODUTOS ALIMENTÍCIOS
}

\author{
F. A. SILVA ${ }^{1}$, C. L. LUNA-FINKLER ${ }^{2}$ e L. FINKLER ${ }^{2}$ \\ ${ }^{1}$ Discente, Universidade Federal de Pernambuco, Centro Acadêmico de Vitória, Núcleo de Nutrição \\ ${ }^{2}$ Docente, Universidade Federal de Pernambuco, Centro Acadêmico de Vitória, Núcleo de Nutrição \\ E-mail para contato: leandro.finkler@gmail.com
}

\begin{abstract}
RESUMO - O desenvolvimento de novos produtos é uma alternativa para conseguir garantir uma alimentação que confira valores nutricionais ao consumidor. A execução racional das etapas de um processo produtivo pode ter êxito pelo emprego das ferramentas de qualidade que, neste trabalho, foram utilizadas para estruturar um plano visando o desenvolvimento de novos produtos. Brainstorming, fluxograma, folha de verificação $(5 \mathrm{~W} 3 \mathrm{H})$ e diagrama de Ishikawa foram as ferramentas adotadas. O Brainstorming possibilitou a identificação de um produto de fácil produção e com grande aceitabilidade, além de auxiliar na identificação das possíveis variáveis que poderão influenciar no desenvolvimento do produto. O fluxograma permitiu observar as etapas pertinentes ao processo e, a descrição destas, identificar as variáveis inerentes. A folha de verificação, considerando como variáveis principais 6Ms (material, método, maquinas, mão-de-obra, meio ambiente e medidas), auxiliou no pensamento macro das influências durante o exercício de produção. O diagrama de Ishikawa ordenou apenas as variáveis secundárias e terciárias que poderiam afetar diretamente a produção. Ao final, foi observado que a variável principal "medida" apontou as variáveis secundárias que, individualizadas em problemas, permitiram detalhar minuciosamente o processo e, assim, apresentar uma sistemática para equipes de pesquisa e desenvolvimento que visem posterior otimização do processo do novo produto.
\end{abstract}

\section{INTRODUÇÃO}

O cenário de desenvolvimento de produtos é complexo e exige multidisciplinaridade para alcançar o objetivo final. Neste sentido, existem diferentes ferramentas/metodologias que podem ser utilizadas para conseguir qualidade ou alcançar objetivos em um ambiente de pesquisa e desenvolvimento. $\mathrm{O}$ uso de ferramentas permite o planejamento, execução e mensuração da atividade para assim conseguir uma metodologia prática e eficiente para o desenvolvimento de um novo produto. O reflexo da utilização das ferramentas da qualidade permitirá a redução do tempo de lançamento de novos produtos no mercado. Contudo, o seu uso, para o desenvolvimento de novos produtos alimentícios, é pouco reportado na literatura científica, exceção a alguns livros que apresentam metodologia (Brody e Lord, 2000) e não estudos de caso. Esta restrição a divulgação certamente está relacionada com a potencialização da competitividade e, por isso, as informações precisam ser resguardadas da concorrência. Essa afirmativa é corroborada por Umemoto et al (2013) 
que, em uma revisão sistemática, observaram em processos de desenvolvimento de produto (PDP) a utilização de ferramentas de qualidade como Diagrama de Ishikawa, Diagrama de Pareto, Histograma, Seis Sigma, DMAIC (Definir, Medir, Analisar, Melhorar e Controlar), CEP (Controle Estatístico de Processo), Análise de Valor/Valor de Engenharia, QFD, Benchmarking e PDCA. Na literatura, o uso tem sido divulgado para o desenvolvimento de pesquisa para reutilização dos resíduos sólidos de coco verde (Fornari Jr., 2010), microplanejamento do serviço de concretagem, gerenciamento de processos industriais (Mariani, 2005), avaliação de defeitos no processo de fabricação de lamelas para pisos de madeira (Coletti et al., 2010). A partir deste cenário, o presente trabalho tem o objetivo de apresentar a utilização de 4 ferramentas da qualidade (Brainstorming, Fluxograma, Folha de Verificação e Diagrama de Ishikawa) como forma de acompanhamento do desenvolvimento de um produto alimentício (picolé probiótico).

\section{METODOLOGIA}

A metodologia utilizada para o desenvolvimento do trabalho foi a das ferramentas da qualidade Brainstorming, Fluxograma, Folha de Verificação e Diagrama de Ishikawa conforme citado em Lins (1993). Na ordem citada, as ferramentas foram utilizadas para conseguir reduzir a um mínimo as informações sobre as variáveis que poderão influenciar no desenvolvimento do novo produto.

\section{RESULTADOS E DISCUSSÃO}

Após a realização do primeiro Brainstorming para definição do produto a ser pesquisado, o picolé foi o produto escolhido, visto a sugestão inicial de ser um produto de fácil aceitabilidade por todas as classes e faixas etárias e no qual fosse possível agregar o conceito probiótico como a característica inovadora. Em seguida foi desenhado o fluxograma do provável processo (Figura 1).

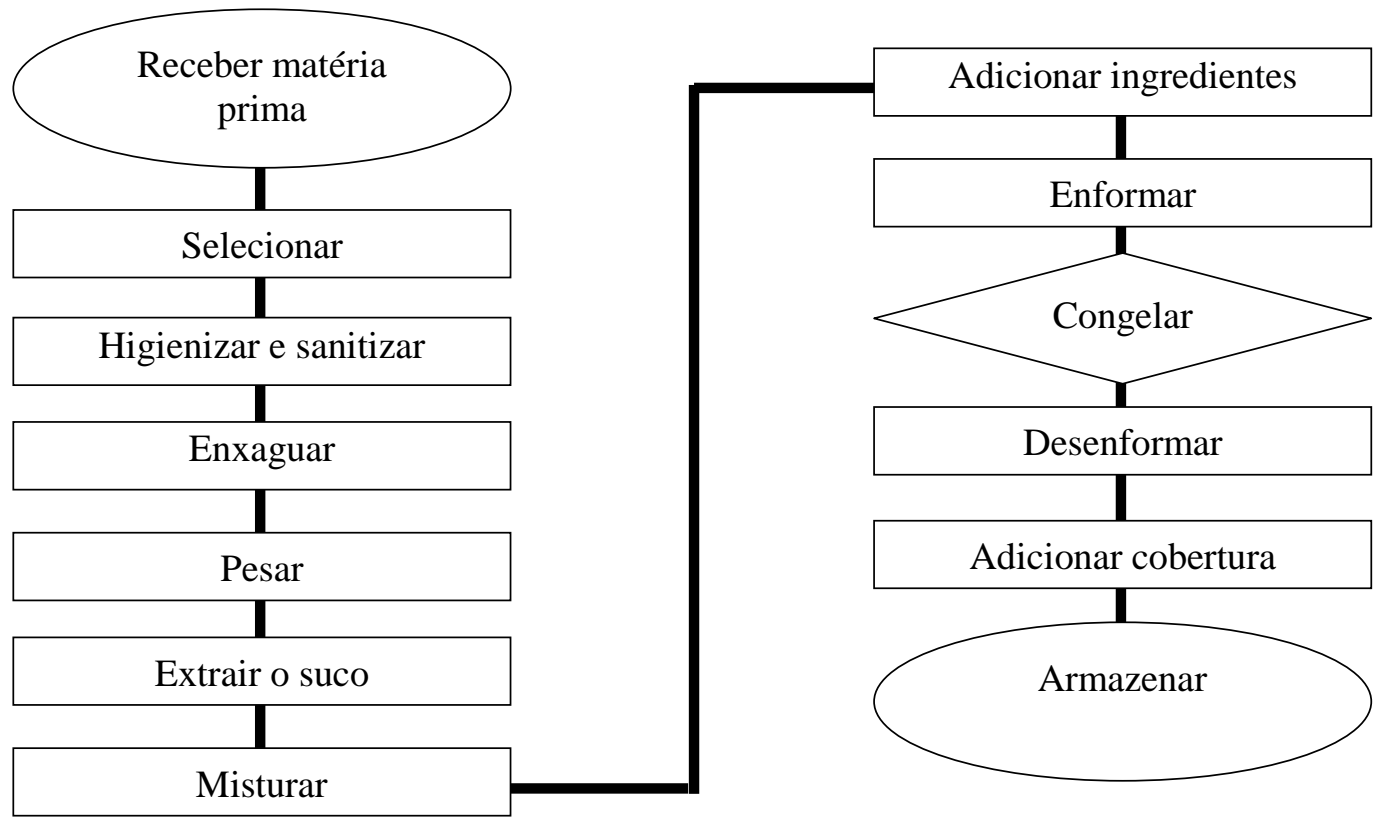

Figura 1. Fluxograma simplificado do processo de produção do picolé probiótico. 
A descrição das etapas apresentadas no fluxograma permitiu um conhecimento técnico prévio para preencher folhas de verificação $(5 \mathrm{~W} 3 \mathrm{H})$ como premissa a estruturação do diagrama de Ishikawa uma vez que foram consideradas como variáveis principais: material, método, meio ambiente, mão de obra, máquinas e medidas. A Tabela 1 apresenta de maneira condensada um formulário com as perguntas que foram realizadas para obter as respostas que em seguida foram submetidas a avaliação do grupo para observação daquelas que poderiam influenciar no desenvolvimento do produto e, assim, compor o diagrama de Ishikawa (Figura 2).

Tabela 1. Formulário condensado da integração das ferramentas folha de verificação $(5 \mathrm{~W} 3 \mathrm{H}) \mathrm{e}$ diagrama de Ishikawa.

\begin{tabular}{llcccccc}
\hline \multirow{2}{*}{ 5W3H } & \multicolumn{9}{c}{ 6M } \\
\cline { 2 - 8 } & MATERIAL & MÉTODO & MEIO AMBIENTE & MÃO DE OBRA & MÁQUINAS & MEDIDAS \\
\hline W $_{1}$ & O QUE & vai comprar & vai fazer & vai organizar & vai contratar & vai comprar & vai medir \\
\hline W $_{2}$ & QUEM & vai fornecer & vai fazer & vai organizar & vai contratar & vai comprar & vai medir \\
\hline W $_{3}$ & ONDE & vai comprar & vai fazer & vai organizar & vai contratar & vai comprar & vai medir \\
\hline W $_{4}$ & QUANDO & vai comprar & vai fazer & vai organizar & vai contratar & vai comprar & vai medir \\
\hline W $_{5}$ & POR QUE & vai comprar & vai fazer & vai organizar & vai contratar & vai comprar & vai medir \\
\hline H$_{1}$ & QUANTO & vai comprar & vai fazer & vai organizar & vai contratar & vai comprar & vai medir \\
\hline H $_{2}$ & QUANTO CUSTA & comprar & fazer & organizar & contratar & comprar & Medir \\
\hline H $_{3}$ & COMO & vai comprar & vai fazer & vai organizar & vai contratar & vai comprar & vai medir \\
\hline
\end{tabular}

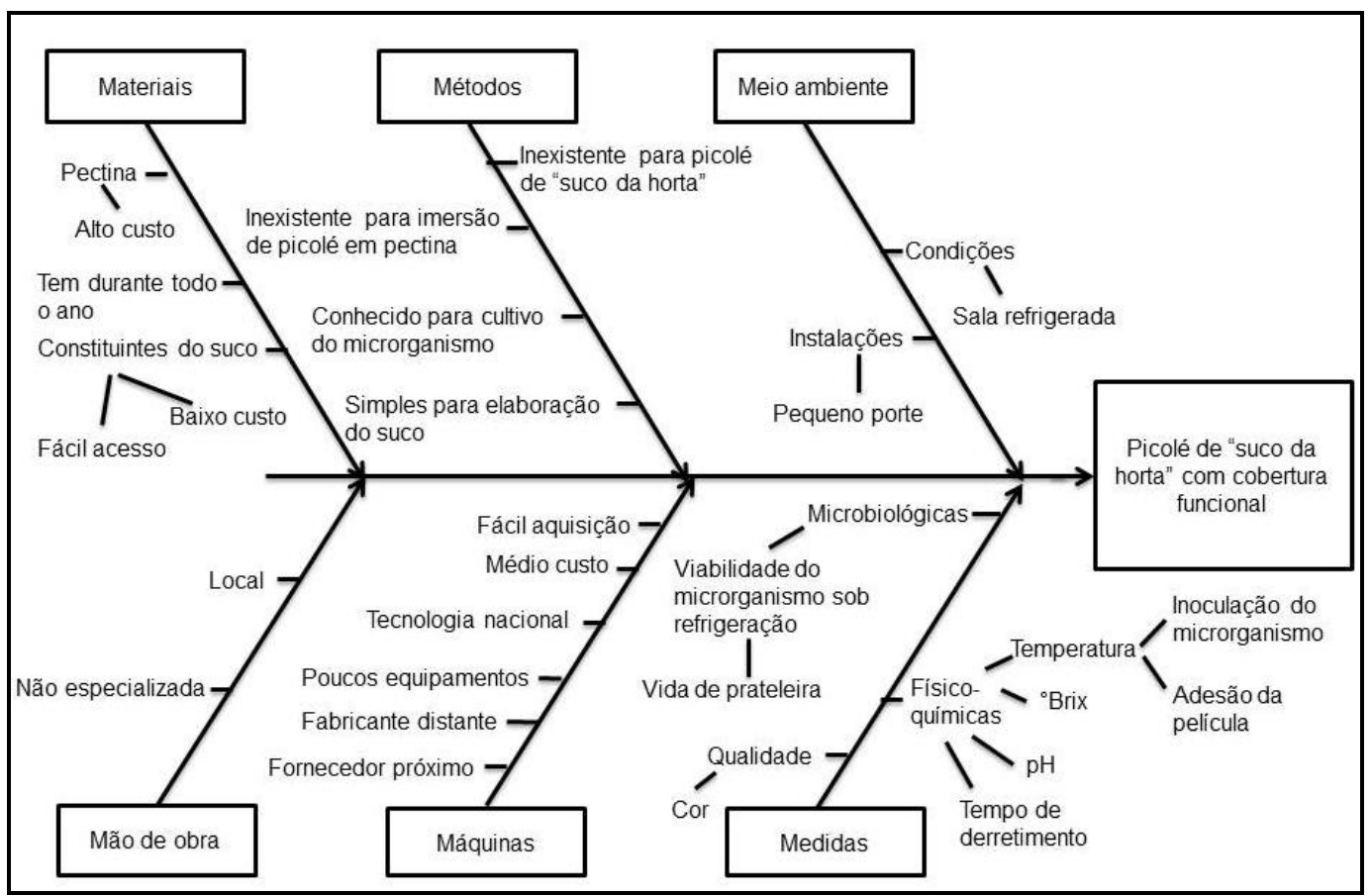

Figura 2 - Variáveis que podem influenciar a produção de picolé probiótico definidas em Brainstorming pré-produção. 
Conforme a Figura 2 permite observar que com relação aos materiais, para compor o suco da horta, são necessárias hortaliça (couve manteiga) e frutas (limão e o maracujá) que são de fácil acesso, baixo custo e produzidos durante todo o ano. O método e a forma de produção do suco é fácil sendo apenas necessário misturar os ingredientes (extratos das frutas e da hortaliça, açúcar). Contudo, a produção de Lactobacillus sp. já é definida, facilitando a obtenção da concentração de microrganismos necessária para compor a cobertura do picolé (De Man, 1960, Luna-Finkler et al., 2014). O ambiente de produção, há necessidade de que a sala possua condições refrigeradas e instalações de pequeno porte. A mão de obra poderá ser local e não precisará ser especializada, pois com um treinamento sobre comportamento (Boas Práticas de Fabricação) e a rotina (Procedimentos Operacionais Padrões) para que foi contratado permitirá ao funcionário executar as atividades necessárias para a produção do picolé. As máquinas ou equipamentos são de fácil aquisição, fácil financiamento e possuem um custo médio. Além disso, há fornecedor próximo às instalações da empresa e a tecnologia é nacional. Quanto às medidas que devem ser realizadas, estas podem ser, de caráter microbiológico, onde será verificada a viabilidade dos microrganismos sob condições refrigeradas estimando a vida de prateleira; ou físico-químico, quando serão medidos o $\mathrm{pH}$, o teor de sólidos solúveis totais $\left({ }^{\circ}\right.$ Brix) e a temperatura, tanto de inoculação do microrganismo quanto da adesão da película no picolé, a fim de atestar a possível influência em relação à cor e ao tempo de derretimento.Esta primeira reflexão sobre o produto, permite antever problemas que eventualmente poderão ocorrer durante a sua produção.

Os ensaios preliminares para a produção do picolé probiótico permitiram observar alguns problemas que foram revelados pelas "medidas" realizadas (Figura 3).

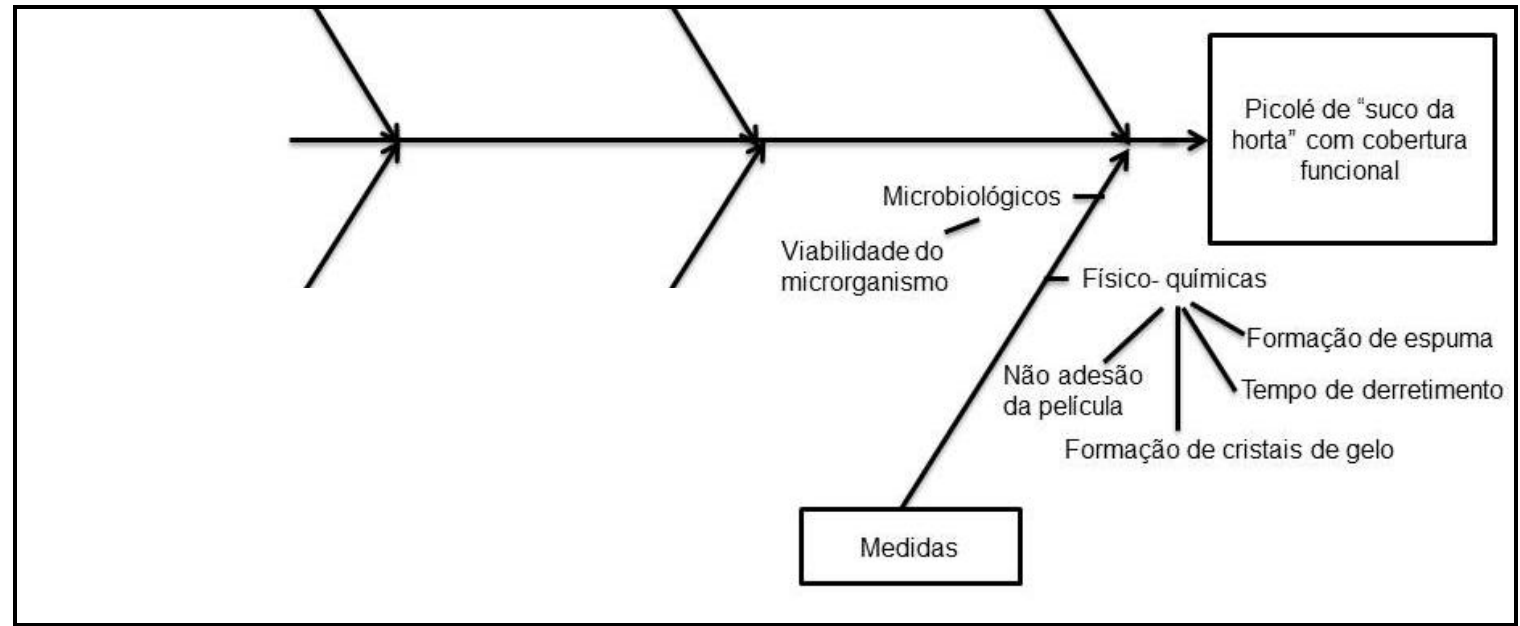

Figura 3- Problemas durante a produção de picolé probiótico.

As causas secundárias identificadas (formação de espuma, formação de cristais de gelo, adesão da cobertura e viabilidade do microrganismo) foram definidas como alvos individuais a serem observados. Importante o fato de ser observado que as medidas são fundamentais durante a realização de qualquer procedimento industrial, uma vez, que foram estas que permitiram assinalar os problemas no processo.

As Figuras 4, 5, 6 e 7 apresentam os digramas de Ishikawa para as causas secundárias. 


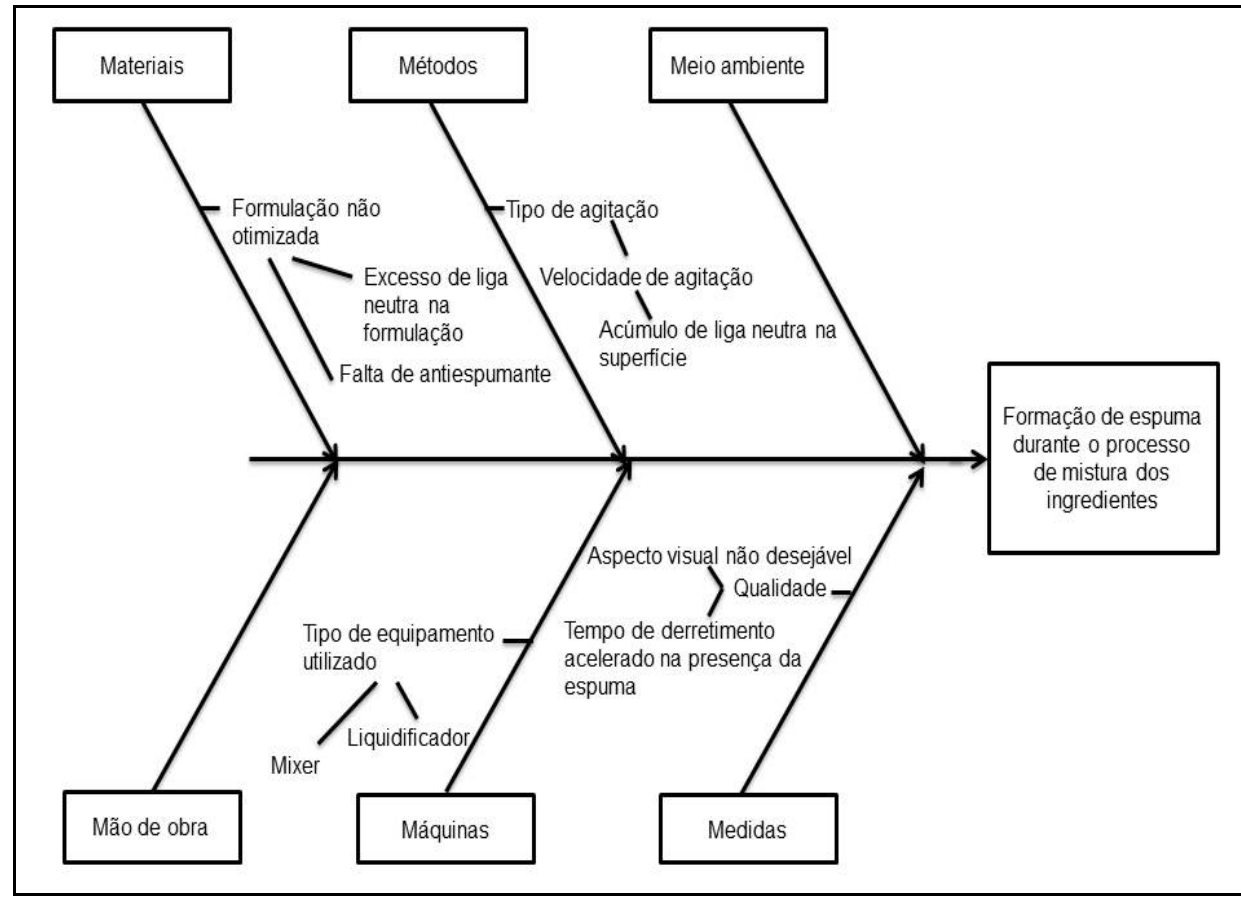

Figura 4- Diagrama de Ishikawa para o problema formação de espuma durante o processo de produção do picolé probiótico.

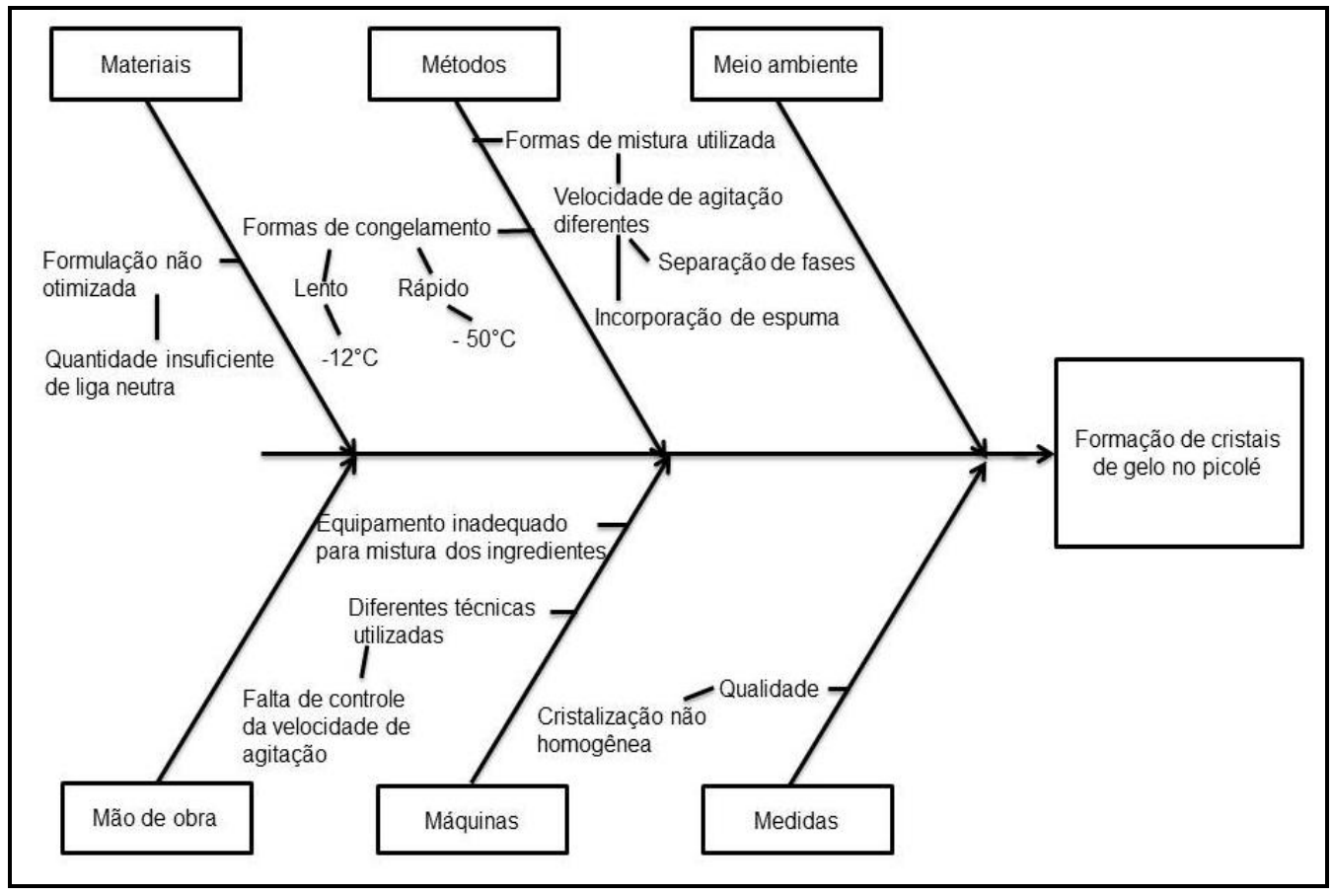

Figura 5- Diagrama de Ishikawa para o problema formação de cristais de gelo durante o processo de produção do picolé probiótico. 


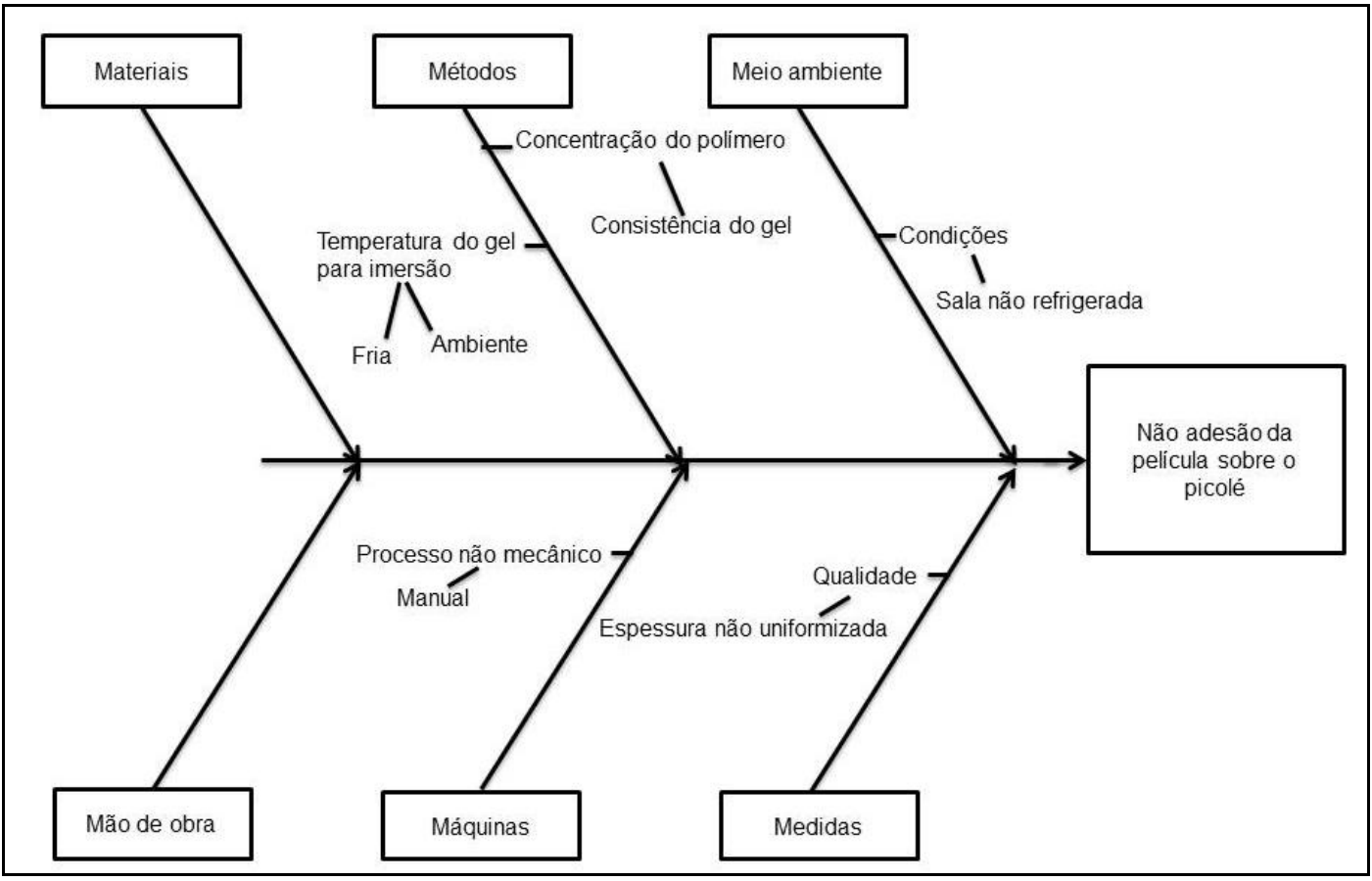

Figura 6- Diagrama de Ishikawa para o problema não adesão da película durante o processo de produção do picolé probiótico.

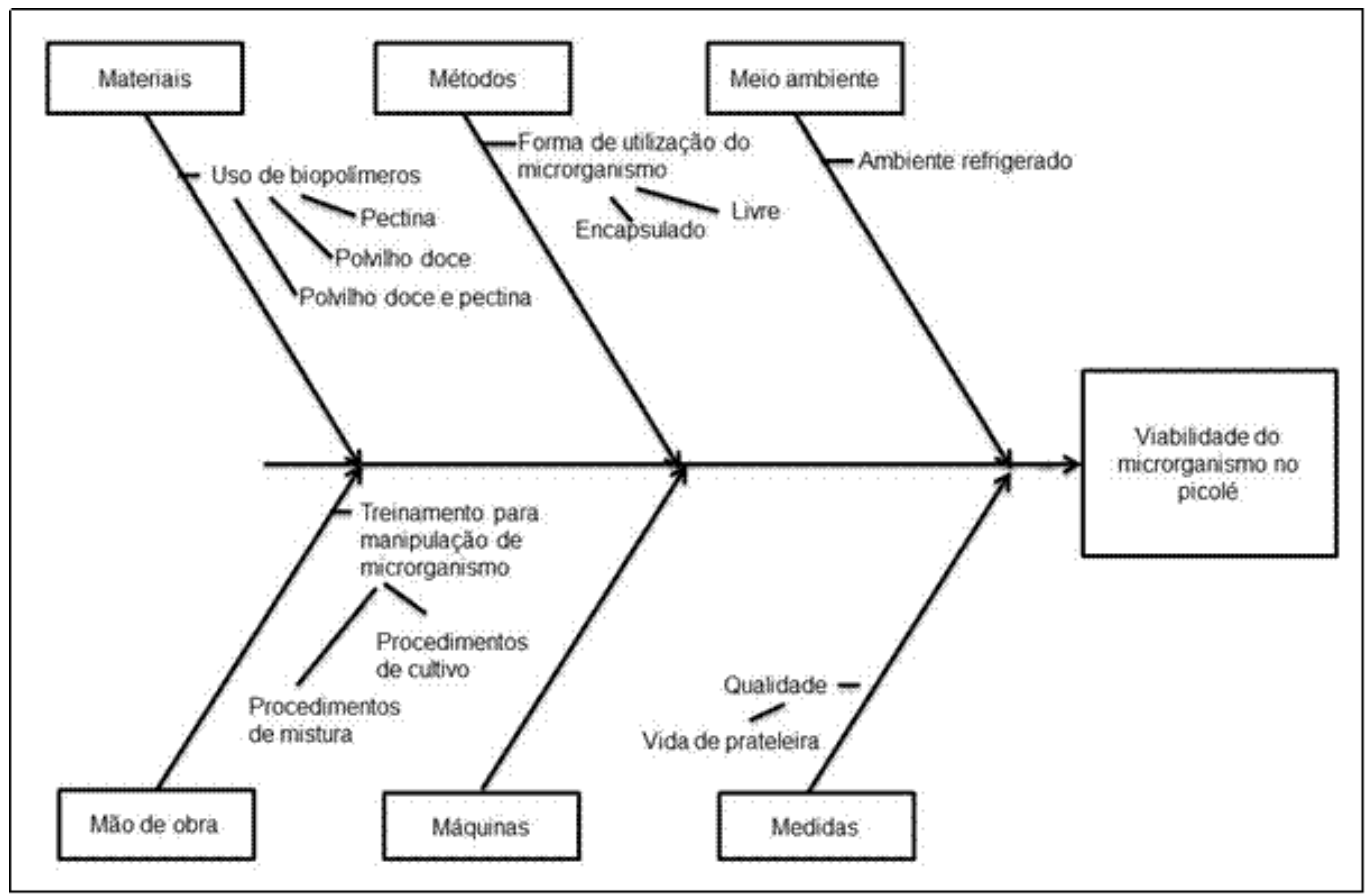

Figura 7- Diagrama de Ishikawa para o problema viabilidade do microrganismo durante o processo de produção do picolé probiótico. 
Observa-se que nos diagramas de Ishikawa para os diferentes alvos problemas nem todas as causas principais tiveram observações que as caracterizassem como importantes para a solução do problema específico. Contudo, estas representações exigirão novos ensaios para garantir a definição da causa responsável pelo problema observado.

\section{CONCLUSÕES}

O trabalho permitiu experimentar as ferramentas da qualidade para o desenvolvimento de um novo produto alimentício. Isto possibilitou desenvolver uma sistemática que fez com que o processo fosse apresentado de maneira minuciosa a partir de observações anotadas na revisão técnica inicial e nos ensaios preliminares. Demonstrou-se, dessa maneira a valorosa contribuição que este tipo de organização pode prestar a equipes de pesquisa e desenvolvimento que visem, em seguida, otimizar as condições do processo na obtenção de novos produtos.

\section{AGRADECIMENTOS}

CAPES, CNPq, PROPESQ/UFPE,CAV/UFPE

\section{REFERÊNCIAS}

BRODY, A.L.; LORD, J.B. Developing new food products for a changing marketplace. London : CRC Press, 2000.

COLETTI, J.; BONDUELLE, G.M.; IWAKIRI, S. Avaliação de defeitos no processo de fabricação de lamelas para pisos de madeira engenheirados com uso de ferramentas de controle de qualidade. Acta Amazônica, v.40, p. 135-140, 2010.

DE MAN, J.C.; ROGOSA, M.; SHARPE, M.E. A medium for the cultivation of Lactobacilli. Journal Applied Bacteriology, v. 23, n. 1, p. 130-135, 1960.

FORNARI JR., C.C.M. Aplicação da ferramenta da qualidade (Diagrama de Ishikawa) e do PDCA no desenvolvimento de pesquisa para a reutilização dos resíduos sólidos de coco verde. Inovação, Gestão e Produção, v. 2, p. 104-112, 2010.

LINS, B.F.E. Ferramentas básicas da qualidade. Ciência da Informação, v. 22, p. 153-161, 1993.

LUNA-FINKLER, C. L.; FINKLER, L.; LOCATELLI, G. O.; LIMA, J. R. Incorporação de Lactobacillus casei microencapsulado em queijo tipo coalho. Revista Ciência \& Saúde, v. 7, n. 1, p. 27-34, 2014. 
MARIANI, C.A. Método PDCA e ferramentas da qualidade no gerenciamento de processos industriais: um estudo de caso. Revista de Administração e Inovação, v. 2, p.110-126, 2005.

UMEMOTO, A.L.T.; LEAL, G.C.L.; CARDOZA, E.; CURCE, J.S.; GOMES, P.F.O. Ferramentas da qualidade no processo de desenvolvimento de produto em PME's: uma revisão sistemática. XXXIII ENGEP, Salvador, BA, out./2013. 